\title{
Depression and Suicide Risk among HIV Positive Individuals Attending an Out Patient HIV/Aids Clinic of a Nigerian Tertiary Health Institution
}

\section{Onyebueke GC and Okwaraji Fe}

Department of Psychological Medicine, College of Medicine, University of Nigeria, Enugu Campus, Nigeria

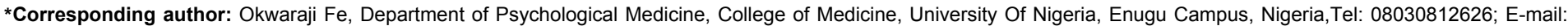
Friday.okwaraji@unn.edu.ng

Received Date: May 12, 2014, Accepted Date: October 8, 2014, Published Date: October 15, 2014

Copyright: () 2015, Onyebueke et al., This is an open-access article distributed under the terms of the Creative Commons Attribution License, which permits unrestricted use, distribution, and reproduction in any medium, provided the original author and source are credited.

\begin{abstract}
Some chronic medical conditions have been found to be worsened by the presence of emotional and psychological disorders which often were not given considerations or even recognized when treatment for these medical conditions are been planned. With regards to HIVIAIDS, the World Health Organization (WHO) had observed that there is a close connection between mental health and HIVIAIDS. The most prevalent mental health problems found to be mostly associated with HIVIAIDS is depression and suicide ideations. This study examined the prevalence of depression and suicide risk among HIV positive persons attending the HIVIAIDS clinic of the University of Nigeria Teaching hospital Enugu south east Nigeria. The major depressive episode and the suicidality modules of the Mini neuropsychiatric interview (MINI) were used to screen 360 persons made up of 180 HIV positive persons and 180 HIV negative blood donors (controls) attending the HIVIAIDS and the hematology clinics of the University of Nigeria Teaching hospital Ituku Ozalla, Enugu south east Nigeria for the prevalence of depression and risk of suicide.
\end{abstract}

The prevalence of depression and risk of suicide was $27.8 \%$ and $7.8 \%$ respectively for the HIV positive subjects, while it was $12.8 \%$ and $2.2 \%$ respectively for the HIV negative blood donors (controls). It was concluded that there was high prevalence of depression and suicide risk among HIV positive persons than among the controls.

Keywords: Depression; Suicide; HIV/AIDS; Psycho education

\section{Introduction}

Genetic research revealed that HIV originated in West Central Africa in the early 20th Centuly [1] but Aids was first clinically observed in the United States in 1981 [2]. The first two cases of AIDS in Nigeria were identified in 1985 and this led Government to initiate programmes aimed at checking the disease [3]. According to the global AIDS response progress report [4] the prevalence rates of HIV and AIDS in Nigeria showed that about $1.8 \%$ of the population were infected with HIV in 1991, 3.8\% in1993, 5.4\% in 1999 and peaked to $5.8 \%$ in 2001 . The report further said that the HIV prevalence has declined steadily throughout the decade. The current prevalence rate was said to be $3.6 \%$ by 2009 [5].

According to the United States president emergency plan for AIDS relief (PEPFAR) [6] the HIV epidemic in Nigeria was complex and varied widely by regions. The report further revealed that in some states the epidemic was more concentrated and driven by high risk behaviors, while other states had more generalized epidemic that are sustained primarily by multiple sexual partnerships in the general population. PEPFAR further posited that youths and young adults in Nigeria were particularly vulnerable to HIV, with young women at higher risk than young men. Someof the risk factors said to be associated with the spread of HIV infection in Nigeria according to the report include prostitution, high risk practices among itinerant workers, high prevalence of sexually transmitted infections, clandestine high risk heterosexual and homosexual practices, international traffickingof women as well as irregular blood screening.
The World Health Organization (WHO) [7], observed that HIV/ AIDS was a significant cause of death and disability especially in low and middle income countries. For instance, the global estimate of AIDS- related deaths in 2010 was said to be 1.8 million, with sub Saharan Africa being the most affected [8]. The world Health Organization further observed that there was a close connection between mental Health and HIV/AIDS, that mental health problems were usually associated with increased risk of HIV infections and that some mental health problems occur as a direct result of HIV infection. Anderson [9] observed that a good understanding of mental health and substance abuse issues will help in protecting people from HIV infection that this will also help to protect those that are already infected from transmitting the virus to others and help to find how to reduce the adverse consequences among those living with HIV. Reports had linked mental health and substance use disorders to increased HIV risk behavior [10,11]

It has been observed that many chronic medical conditions were most often exacerbated by emotional and psychological disorders and in most cases the emotional aspects of such chronic medical conditions were often neglected when medical interventions were been considered $[12,13]$. For instance, Rodin and voshart [14] argued that depressive symptoms were common in the medically ill, although they were frequently unrecognized and untreated. According to the DSMIV-TR of the American Psychiatric association [15] the essential features of a major depressive episode is a period of at least two weeks during which there is either depressed mood or the loss of interest or pleasure in nearly all activities. It went further to say that the individual must also experience at least four additional symptoms drawn from a list that includes changes in appetite or weight, sleep and 
psychomotor activity, decreased energy, feeling of worthlessness or guilt, difficulty thinking, concentrating, recurrent thoughts of death or suicidal ideation, plans or attempt. It has been observed that in the context of HIV/AIDS, depression is an often overlooked but potentially dangerous condition that can influence quality of life, relationships, employment and adherence to medical care [16].

Rabkin 16 further argued that depression was associated with isolated lives the absence of pleasure as well as social' and vocational impairment. Furthermore, that apart from substance use disorders, depression was the most prevalent psychiatric disorder among HIVPositive adults [16]. Ickovics et al. [17] reported that depressive symptoms among women with HIV were associated with HIV disease progression, even when the effects of key clinical, substance use and socio demographic characteristics were controlled. They also found that symptoms of depression were equally associated with unprotected sexual intercourse, multiple sex partners, trading sex for money or drugs, and contracting sexually transmitted diseases. It had equally been observed that depression may combine with the effects of other psychosocial factors to produce a set of interrelated health problems experienced by a single individual. For instance Stall et al. [18] studied a group of men who had sex with men to test whether some specific set of psychosocial health conditions like depression, poly drug use, childhood sexual abuse and partner violence had influence on the HIV/AIDS epidemic among men who had sex with men.

Their report revealed that all the four psychosocial health problems were significantly associated with a greater likelihood of high-risk sexual behavior and of having HIV. They also found that individuals with depressive symptoms, poly drug use and childhood sexual abuse were at higher risk of having HIV than those with only depressive symptoms and poly drug use. Furthermore individuals with depressive symptoms and poly drug use were at higher risk than those with depressive symptoms alone. According to the world Health Organization 7, people with HIV often suffer from depression and anxiety as they adjust to the impact of the diagnosis of being infected and face the difficulties of living with a chronic life threatening illness, such as shortened life expectancy, complicated therapeutic regimens, stigmatization and loss of social support, family or friends. The WHO equally observed that HIV infection can be associated with high risk of suicide or attempted suicide. According to this global Health body, the psychological predictors of suicidal ideation in HIV- infected individuals include concurrent substance use disorders, past history of depression and presence of hopelessness. Studies had reported prevalence of depressive disorder in HIV infected individuals. For instance Rosenberg et al. [19] compared HIV seropositive individuals with matched HIV seronegative controls and reported a high prevalence of depressive disorders in both the affected individuals and the controls. They concluded that infection was occurring in groups of individuals already at a high risk of depressive disorders such as homosexuals and intra venous drug users.

In a related study Morrison et al. [20] Studied depressive and anxiety disorders in women with HIV in the USA compared with a control. Result showed a $19.4 \%$ current major depressive episode among the HIV positive women and a $4.8 \%$ major depressive episode among the controls indicating an almost 4:1 prevalence of depression between the HIV infected women and the control group. Furthermore Nogueira et al. [21] assessed 386 HIV infected persons in Brazil for depression before the introduction of antiretroviral therapy, using the Hospital anxiety and depression scale (HAD), and reported a $21.8 \%$ prevalence of depression. Furthermore they found out that some of the associated risk factors for depression among their subjects include female gender, low educational attainment, and low income, having no social partner for an average of 1 month prior to the study and having no health insurance. Other studies had equally reported high prevalence of depression among HIV positive individuals [22-24].

Reporting from Kenya, Sebit [25] in a WHO multinational survey done in Kenya compared HIV seronegative and seropositive individuals found no statistically significant increase in the prevalence of depressive disorders among the two groups.

Whereas Ovuga et al. [26] surveyed 46 HIV/AIDS patients aged 24-56 years for depression at the AIDS support organization clinic in Malaga Hospital Kampala, Uganda, and found a total prevalence of psychiatric disorder of $82.6 \%$. The most common psychiatric disorders found were major depression (54.3\%) and panic disorder (32.6\%). They also reported $13 \%$ increased risk of suicidal ideas among the subjects. Furthermore Oley et al. [27] in their own study investigated the prevalence of psychiatric morbidity among 149 HIV seropositive persons in Cape Town and reported that $4.6 \%$ of the patients were diagnosed with psychiatric disorders, most commonly major depression. Petrushkin et al. [28] working in outpatient HIV/AIDS clinic in Uganda interviewed 45 HIV seropositive patients and reported a total prevalence of $82.6 \%$ of mental disorders among the subjects with $10.1 \%$ of them having chronic depression and $13 \%$ current suicidal ideation. The information on the prevalence of psychiatric disorders among HIV/AIDS patients in Nigeria had been limited. However depressive disorder had received more attention than other disorders. For instance Sale et al. [29] in a descriptive and cross-sectional study, at the Aminu Kano Teaching Hospital in Northern Nigeria reported a $39.9 \%$ prevalence of depression among HIV/AIDS patients aged 15-25 years. Furthermore Ndu et al. [30] in their own study at the out- patient HIV/AIDS clinic of the University of Nigeria Teaching Hospital, Enugu South East Nigeria found a 20\% prevalence of depression among the 122 subjects who took part in the study. The authors reported that factors such as lack of social support and not belonging to a social group were associated with depression. In a related study Olisa et al. [31] reporting from Ahmadu Bello University Teaching Hospital in North Central Nigeria found a depression prevalence of $14.2 \%$ among 310 seropositive patients attending the out-patient HIV/AIDS clinic of the hospital.

Several studies have reported rates of suicidal ideations and attempts among patients with chronic medical conditions especially AIDS. In most of these studies depression and HIV/AIDS featured prominently as important risk factors for suicide [32-34]. For instance Marzuk et al. [35] studied the prevalence of suicide among HIV seropositive persons in New York by reviewing the data of 1875 suicide victims. They reported that $9 \%$ of the suicide victims were HIV positive individuals.

Other studies had equally reported higher rates of suicidal behavior or attempts among HIV positive people than in the general population [36-38]. Furthermore studies have shown increased risk of suicide in patients with or without HIV disease suffering from major depressive disorder [38,39]. Perry et al. [40] opined that depression is a high risk factor for attempted suicide and suicidal ideations in HIV/AIDS patients.

In the light of the foregoing, giving the relatively paucity of data on the prevalence of depressive disorder and suicide risk among HIV/ AIDS patients in Nigeria, the present study is an attempt to determine the prevalence of depression and risk of suicide among a sample of 
HIV/AIDS patients attending the HIV/AIDS clinic of a Nigerian Tertiary Health institution with a view to making more data available on this subject, compare the data with what had been reported elsewhere and make some suggestions on how to reduce or mitigate the prevalence of depression and risk of suicide among HIV/AIDS patients. This will also help in reducing the sufferings already being experienced by the HIV/AIDS patients and add to the health promotion campaign of the government.

\section{Method}

Study Design: This is a case- control study carried out at the HIV/ AIDS clinic of the University of Nigerian Teaching Hospital ItukuOzalla, in Enugu State South- East Nigeria between March and August 2013.

Study Setting: The study was carried out in the HIV/AIDS outpatient clinic of University of Nigeria Teaching Hospital (UNTH) Ituku Ozalla, Enugu, in Enugu State South East Nigeria. Enugu State is a mainland State in South East Nigeria. It has very large deposits of coal, hence it is also known as the coal city state. It occupies an area of about 7, 161 square kilometers. The state has a population of about $5,590,513$.

The University of Nigeria Teaching Hospital Ituku Ozalla is a federal tertiary health institution and a center of excellence in healthcare delivery in south eastern region of Nigeria. It serves virtually all the five South eastern states and beyond. The hospital has 500 bed capacity and 21 clinical departments. It covers an area of about 200 acres of land. The hospital is one of the federal government's of Nigeria designated centers for the treatment of HIV/ AIDS. The HIV/AIDS clinic has over 5000 registered HIV/AIDS patients. Presently the center is being supported by the former United States president and the Harvard School of public health under the name of PEPFAR. The center runs 5 day clinic services for HIV/AIDS patients per week. It has an average daily clinic attendance of 30 patients.

\section{Subjects}

Subjects for the study were HIV positive patients attending the HIV/AIDS clinic of the University of Nigeria Teaching Hospital ItukuOzalla Enugu, South East Nigeria. They were aged between 15-65 years. There was equally a control group of subjects of the same age range made up of HIV negative individuals selected from blood donors at the blood donation section of the hematology department of the hospital with a daily average of 12 blood donors. Using the formula for minimum sample size calculation for a prevalence study [41] a total of 360 patients made up of $180 \mathrm{HIV}$ positive patients and 180 HIV negative blood donors were selected using simple random sampling method. For the HIV positive subjects inclusion criteria were, confirmed HIV positive cases using ELISA and western Blot technique; those between ages 15-65, and patients who agreed and signed the consent form to participate in the study. Exclusion criteria were patients who were too ill to participate, those outside the age range of 15-65 years, those with a previous DSM-IV axis I diagnosis of depression and those who declined consent.

Furthermore, inclusion criteria for the control group were, donors who were screened to be HIV negative by Elisa, Confirmed by western Blot technique; donors who were between 15-65 years and donors who signed the consent form to participle in the study. Whereas exclusion criteria for the control group were donors screened to be HIV positive, those who did not give their consent, were outside the age range of 15-65 years and donors with a previous history of depression following DSM- IV axis I diagnosis. The purpose and procedure of the study was fully explained to them. They were assured that their responses will be treated confidentially, and no respondent will be identified in person and that participation was voluntary. Furthermore all the subjects were assured that non participation will not in any way prevent them from receiving their clinical services.

All the subjects agreed and signed the consent form indicating their willingness to participate in the study after all the explanations. Ethical approval for this study was duly obtained from the University of Nigeria Teaching Hospital Ethical Committee. Data Collection and Instruments: Data for this study was collected by the authors with the help of two post graduate clinical psychology interns and a resident doctor in psychiatry, who were very conversant with the use of the screening instruments. The instruments for data collection were made up of two parts. Part one was a socio-demographic questionnaire, part two was the major depressive episode and suicidality modules of miniinternational neuropsychiatric interview (MINI) [42]. The sociodemographic questionnaire: This questionnaire was designed to obtain data from the subjects regarding some socio-demographic variables like age, sex, educational level, religious affiliation, marital status and area of residence.

The Mini-International Neuropsychiatric Interview (M.I.N.I): This is a short structured diagnostic interview which was developed for assessing psychiatric disorders based on DSM-IV and ICD-10 criteria. With an administration time of approximately 15 minutes, the MINI was designed to meet the need for a short but accurate structured psychiatric interview for multicenter clinical trials and epidemiological studies. It is expected to be used as a first step in outcome tracking in non research clinical settings. This instrument had been widely used by health professionals and organizations and had been translated in many languages. The mini has many modules for diagnostic categories but only the major depressive episode and the suicidality modules were used in this study. The major depressive episode module of MINI which was grouped as 'A-Module' is made up of six sections ranging from A1 to A6. However in this study questions A1-A3 were used since the study assessed major depressive episode (current). Furthermore the suicidality module of MINI, also known as the ' $\mathrm{C}$ module' was used in this study. This module is made up of 9 questions ranging from $\mathrm{C} 1$ to $\mathrm{C} 9$. Questions $\mathrm{C} 1$ to $\mathrm{C} 8$ were used to assess events in the past one Month, while question C9 was used to assess for suicide attempt in a patient's life time. The module assessed suicidal behavior including intent, plan and attempt. Scores ranging from 1-8 points indicates low suicide risk, 9-16 points indicates moderate suicide risk, while scores greater than 17 points indicates high suicide risk. Both the major depressive episode and the suicidality modules of the MINI had been used for studies in Nigeria 13

\section{Data Analysis}

Data for this study was analyzed using SPSS version 16.0. Chi square test, t-test and fisher's exact test were used to analyze categorical variables. The level of significant chosen for this study was P 0.05 . 
Citation: Onyebueke GC and Okwaraji Fe (2015) Depression and Suicide Risk among HIV Positive Individuals Attending an Out Patient HIV/ Aids Clinic of a Nigerian Tertiary Health Institution . J Psychiatry 18: 182. doi:10.4172/2378-5756.1000182

Page 4 of 8

\section{Results}

\section{Socio-demographic characteristics of the subjects}

A total of 360 subjects made up of 180 HIV/AIDS positive persons and $180 \mathrm{HIV/AIDS}$ negative Controls took part in the study. For ease of understanding the HIV/AIDS positive subjects are hereby referred to as "cases" while the HIV/AIDS negative subjects are hereby referred to as "controls". Among the cases 64 (35.6\%) were males while 116 (64.4\%) were females. For the control subjects 156 (86.7\%) were males while $24(13.3 \%)$ were females. This was significant $x^{2}=98.3, d f=1$, $\mathrm{P}<0.01$.
Their age range was 15-65 years, with a mean age of 38.0 \pm 9.44 for the cases and $28.9 \pm 7.23$ for the controls. This was equally significant, $\mathrm{t}=10.07 ; \mathrm{p}=0.01$. With regard to marital status; 131 (72.8\%) of the cases were married, while 49 (27.2\%) were never married. Furthermore, $45(25.0 \%)$ of the controls were married as against 135 (75.0\%) who were never married $\left(\mathrm{x}^{2}=11.478, \mathrm{df}=4, \mathrm{P}=0.01\right)$. In the area of education it was discovered that $7(3.9 \%)$ of the cases as well as $4(2.3 \%)$ of the controls had no formal education $\left(\mathrm{x}^{2}=53.1 ; \mathrm{p}=0.00\right)$.

The socio-demographic characteristics of the subjects are shown in Table1 below.

\begin{tabular}{|c|c|c|c|}
\hline Variables & Cases & Controls & Statistics \\
\hline Gender & $N(\%)$ & $n(\%)$ & \\
\hline Male & $64(35.6)$ & $156(86.7)$ & $x 2=98.3$ \\
\hline Female & $116(64.4)$ & $24(13.3)$ & $P=0.01^{* *}$ \\
\hline \multicolumn{4}{|l|}{ Age(years) } \\
\hline $15-24$ & $9(5.1)$ & $37(20.6)$ & \\
\hline $25-34$ & $68(37.8)$ & $117(65.5)$ & \\
\hline $35-44$ & $73(40.4)$ & $20(11.1)$ & \\
\hline $45-54$ & $18(10.0)$ & $4(2.2)$ & \\
\hline $55-65$ & $12(6.7)$ & $2(1.1)$ & $t=10.17$ \\
\hline Mean + SD & 38.09 .44 & 28.97 .23 & $p=0.00^{\star \star *}$ \\
\hline \multicolumn{4}{|l|}{ Marital Status } \\
\hline Married & $131(72.8)$ & $45(25.0)$ & $X 2=11.478$ \\
\hline Not Married & $49(27.2)$ & $135(75.0)$ & $P=0.01^{* *}$ \\
\hline \multicolumn{4}{|l|}{ Educational } \\
\hline \multicolumn{4}{|l|}{ Attainment } \\
\hline \multicolumn{4}{|l|}{ No formal } \\
\hline Education & $7(3.9)$ & $4(2.3)$ & $x 2=53.1$ \\
\hline Formal Education & 173(96.1) & 176(97.7) & $P=0.00^{* * *}$ \\
\hline \multicolumn{4}{|l|}{ Religion } \\
\hline Christianity & $173(96.1)$ & $152(84.4)$ & $x 2=32.4$ \\
\hline ATR & $7(3.9)$ & $28(15.6)$ & $P=0.01^{* *}$ \\
\hline \multicolumn{4}{|l|}{ Area of Residence } \\
\hline Urban & $116(61.1)$ & $69(38.9)$ & $x 2=25.9$ \\
\hline Rural & $69(38.9)$ & $27(15.0)$ & $P=0.01^{* *}$ \\
\hline
\end{tabular}

Table 1: Socio - demographic characteristics of the subjects. ATR $=$ African Traditional Religion ${ }^{*}{ }^{* *}$ and ${ }^{* * *}=$ Significant.

Prevalence of Depression (Current Episode) and Risk of Suicide among the Cases and the Control Subjects.

With regards to prevalence of depression among the subjects, the authors found that $50(27.8 \%)$ of the cases had depression as against 23
(12.85) of the controls. This was significant. $\left(\mathrm{x}^{2}=12.5\right.$; df $\left.1 ; \mathrm{p}=0.01\right)$. Furthermore, it was discovered that $14(7.7 \%)$ of the cases as against $3(1.7 \%)$ of the controls exhibited risk of suicide but this was not significant even though risk of suicide was shown bymore number of the "cases" on the suicidality module of the MINI. 
Page 5 of 8

Table 2 shows the prevalence of depression and risk of suicide among the subjects.

\begin{tabular}{|l|l|l|l|}
\hline Cases & Controls & Statistics & \\
\hline & $\mathrm{N}(\%)$ & $\mathrm{N}(\%)$ & \\
\hline Depression & $50(27.8)$ & $\begin{array}{l}23(12.8) \times 2 \\
12.5\end{array}$ & $\mathrm{P}=0.01^{*}$ \\
\hline Risk of suicide & $14(7.8)$ & $3(2.2) \times 2=0.4$ & $\mathrm{P}=0.68$ \\
\hline
\end{tabular}

Table 2: Depression (current episode) and risk of suicide among the "cases" and the control subjects ${ }^{*},{ }^{* *}$ and ${ }^{* * *}=$ Significant

Association between Depression and Socio-Demographic Characteristics among the "Cases" and the "Controls".

Table 3 shows the association between depression and sociodemographic characteristics among the cases and the controls.

With regards to age, it was found that 29 (58.0\%) of the cases below the age of 40 years had depression as against $19(82.6 \%)$ of the controls, whereas $21(42 \%)$ of the cases who were above 40 years of age compared to $4(17.4 \%)$ of the controls were found to be depressed. This was significant, $\left(\mathrm{x}^{2}=4.2, \mathrm{P}=0.04\right) .22(44.06 \%)$ of the male cases compared to $19(82.6 \%)$ of the male controls reported being depressed, whereas $28(56.0 \%)$ of the female cases as against $4(17.4 \%)$ of the female controls also had depression. This report revealed that for the cases more females were depressed than their male counterpart, whereas for the controls more males were depressed than their female counterpart.

In the area of marital status the authors found that 29 (58.0\%) of the cases and $5(21.7 \%)$ of the controls who were married had depression. Whereas $21(42.0 \%)$ of the cases and $18(78.3 \%)$ of the controls who were single/divorced also had depression. This was also significant $\mathrm{x}^{2}=11.9, \mathrm{P}=0.01$. Equally 19 (38. $\left.0 \%\right)$ of the cases and 21 (91.3\%) of the controls who had low educational attainment were found also to be depressed, whereas $31(62.0 \%)$ of the cases and $2(8.7 \%)$ of the controls with high educational attainment were depressed. Depression was also noticed among $32(64.0 \%)$ of the cases and $10(43.5 \%)$ of the controls who were employed, compared to 18 (36.6) of the cases and $13(56.5 \%)$ of the controls who were unemployed, though this was not significant. $\left(\mathrm{x}^{2}=2.7, \mathrm{P}=0.09\right)$.

In terms of area of residence result revealed that 26(52.0\%) of the cases and $21(91.3 \%)$ of the controls who resided in the urban areas had depression, while, $24(48.0 \%)$ of the cases and $2(8.7 \%)$ of the controls residing in the rural area had depression and this was significant $\mathrm{x}^{2}=10.6, \mathrm{P}=0.01$. This was shown in Table 3 below.

Furthermore, among the cases 14 (28\%) had risks of suicide whereas $36(72 \%)$ had no risk of suicide. Whereas among the control subjects with depression, $3(13.0 \%)$ had risk of suicide as against 20 $(87.0 \%)$ who had no risk of suicide.

Table 4, shows the association between socio-demographic characteristics and risk of suicide among the "cases".

\section{Discussion}

Studies had revealed that burden of many chronic medical conditions were often complicated by co-morbidity with some emotional and psychological disorders and in most cases the emotional aspects of such chronic medical conditions were neglected when considering medical interventions $[12,13,43]$.

\begin{tabular}{|l|l|l|l|}
\hline Variable & Cases & Controls & Statistics \\
\hline Age (years) & $\mathrm{n}(\%)$ & $\mathrm{n}(\%)$ & \\
\hline$<40$ & $29(58.0)$ & $19(82.6) \times 2=4.2$ & $\mathrm{P}=0.04^{*}$ \\
\hline$>40$ & $21(42.0)$ & $4(17.4)$ & \\
\hline Sex & & & \\
\hline Male & $22(44.0)$ & $19(82.6) \times 2=9.6$ & $\mathrm{P}=0.01^{* *}$ \\
\hline Female & $28(56.0)$ & $4(17.4)$ & \\
\hline Marital status & & & \\
\hline Single/Divorced & $21(42.0)$ & $18(78.3) \times 2=11.9$ & $\mathrm{P}=0.01^{* *}$ \\
\hline Married & $29(58.0)$ & $5(21.7)$ & \\
\hline Education & & & $\mathrm{P}=0.01^{* *}$ \\
\hline Low Education & $19(38.0)$ & $21(91.3) \times 2=18.1$ & $\mathrm{P}=0.01^{* *}$ \\
\hline High Education & $31(62.0)$ & $2(8.7)$ & \\
\hline Employment & & & $\mathrm{P}=0.09$ \\
\hline Employed & $32(64.0)$ & $10(43.5) \times 2=2.7$ & \\
\hline Unemployed & $18(36.0)$ & $13(56.5)$ & \\
\hline Area \\
Residence
\end{tabular}

Table 3: Association between depression and Socio- demographic characteristics among the "cases" and the "controls". ATR=African traditional Religion. , Note: ${ }^{*}$ and $^{* *}=$ Significant

This study had revealed that depression and suicide risk were prevalent among the subjects studied. But the prevalence was much higher among the cases than the controls. For instance $27.8 \%$ of the cases as against $12.8 \%$ of the controls were found to be depressed, similarly $7.8 \%$ of the cases as against $2.2 \%$ of the controls were equally found to have risk of suicide. This finding was in line with previous studies. For instance Rosenberg et al. [19] in their study reported a higher prevalence of depression among HIV positive patients than among the controls. Similarly Kelly et al. [44] in their study in Australia reported a $29 \%$ rate of suicide among the HIV positive subjects as against $21 \%$ risk of suicide found among the HIV negative subjects who served as controls. Other studies had equally reported high prevalence of depression among HIV/AIDS patients compared to general population $[25,27,34]$. Rabkin 16 had argued that in the context of HIV/AIDS depression was an often overlooked but potentially dangerous condition that can influence not only quality of life but 
adherence to medical care, employment, and social relationships. Furthermore according to WHO7 some of the psychological predictors of suicidal ideation in HIV infected individuals include concurrent substance use disorders, past history of depression and presence of hopelessness. The increased risk of suicide found among the 'cases' may be attributed to stress associated with HIV infection, stigmatization at home and place of work, lack of social support especially among those living in the rural areas, death of spouse or children. Other studies had equally reported risks of suicide among HIV/AIDS patients compared to general population $[45,46]$. It should also be noted that this high prevalence of depression noticed among the 'cases' may not only be attributed to their HIV/AIDS status but may be as a result of the anti-retroviral medication coupled with the burden of illness associated with HIV/AIDS which may equally affect their mood and make them feel depressed.

\begin{tabular}{|c|c|c|c|}
\hline Variable & Risk of Suicide No Risk of Suicide & Statistics & \\
\hline & $\mathrm{n}(\%)$ & $\mathrm{n}(\%)$ & \\
\hline \multicolumn{4}{|l|}{ AGE (Years) } \\
\hline$<40$ & $11(78.6 \%)$ & $70(42.2) \times 2=6.9$ & \\
\hline$>40$ & $3(21.4)$ & $96(57.8)$ & \\
\hline \multicolumn{4}{|l|}{ Sex } \\
\hline Male & $3(21.4)$ & $63(38.0) \times 2=1.3$ & $P=0.23$ \\
\hline Female & $11(78.6)$ & $103(62.0)$ & \\
\hline \multicolumn{4}{|l|}{ Marital Status } \\
\hline Married & $10(71.4)$ & $110(66.3) \times 2=0.1$ & $P=0.69$ \\
\hline Single & $4(28.6)$ & $56(33.7)$ & \\
\hline \multicolumn{4}{|l|}{ Education } \\
\hline Low & $5(35.7)$ & $11(6.6) \times 2=13.5$ & $P=0.01^{* *}$ \\
\hline High & $9(64.3)$ & 155(93.4) & \\
\hline \multicolumn{4}{|l|}{ Employment } \\
\hline Employed & $10(71.4)$ & $101(60.8) \times 2=0.6$ & $P=0.43$ \\
\hline Unemployed & $4(28.6)$ & $65(39.2)$ & \\
\hline \multicolumn{4}{|l|}{ Residence } \\
\hline \multirow[t]{2}{*}{ Urban } & $6(42.9)$ & $46(27.7) \times 214$ & $P=0.23$ \\
\hline & $8(57.1)$ & $120(72.3)$ & \\
\hline \multicolumn{4}{|l|}{ Religion } \\
\hline Christian & $13(92.9)$ & $165(99.4) \times 2=5.0$ & $P=0.03^{*}$ \\
\hline ATR & $1(7.1)$ & $1(0.6)$ & \\
\hline
\end{tabular}

Table 4: Association between socio demographic characteristics and risk of suicide among the Cases, Note: ${ }^{*}$ and ${ }^{* *}=$ Significant, ATR=African traditional Religion.

With regards to age; the study found that more of the cases as against the controls were below the age of 40 years, that is, those in the younger age bracket. This finding corroborates that of Sale and Gudany 29 who equally noticed a $39.9 \%$ prevalence of depression among the HIV/AIDS subjects they studied aged 15-25 years. The high prevalence of depression noticed among the younger subjects in this study may be due to the fact that younger people are usually more sexually active than the elderly ones, and they may likely indulge more in high risk sexual behaviors like having unprotected sex which may eventually increase their chances of contracting sexually transmitted diseases including HIV. The diagnoses of being HIV positive may then make them to become depressed. In this regard PEPFAR6 had argued that the youths and young adults in Nigeria were particularly vulnerable to HIV infection due to high risk behaviors like clandestine heterosexual and homosexual practices and substance abuse. Regier et al. [47] had earlier reported increased rate of depression among young people.

With regards to sex, the authors found that there were more females $56.0 \%$, than males $44.0 \%$ in the "cases" with depression, whereas there were more males $19(82.6 \%)$ than females $4(17.4 \%)$ in the "controls" with depression. With regards to the "cases" it had been observed that 
women with HIV/AIDS were at significantly greater risk than men to develop major depressive episode at some point during their lives, and that mood disorders in general were much more common in females than men, with the pattern of difference between the sexes being consistent across different cultures [48].

Furthermore Ickovics et al. [17], had argued that depressive symptoms among women with HIV were associated with HIV disease progression even when the effects of key clinical, substance use and socio-demographic characteristics were controlled.

The harsh economic condition in the country and too much quest for material things may push younger women to indulge in risky sexual habits like having multiple sexual partners, exchanging sex for money without taking adequate precautions to protect themselves like consistent condom use, from contracting HIV infection which will incidentally predispose them to being depressed. The higher men than female depression rate noticed among the controls may be as a result of stressful life events like unemployment which may impact more negatively among the males than the females.

Among the "cases" it was found that 29 (58.0\%) were married as against 21 (42.0) who were single/divorced. The high rate of depression noticed among the 'cases' that were married may be as a result of increased burden this illness placed on the patients who may no longer meet up with the obligation of providing adequate financial support to their family as much money may be spent on buying drugs to address the HIV/AIDS disease, thereby leaving little or nothing for the up keep of the family members like payment of school fees and feeding the children.

$26(52.0 \%)$ of the cases were found to reside in urban areas. It would appear that many urban dwellers were mostly youths and students who seem to be more sexually active and adventurous without minding the consequences of clandestine sexual practices.

\section{Conclusion}

This study had revealed the presence of depression and risk of suicide among HIV positive individuals in south eastern Nigeria.

\section{Recommendation}

There is need for government to integrate mental health care in the overall physical management of people found to be HIV positive as well as those with HIV/AIDS disease as this will help to capture the mental health component of this pandemic and reduce complications arising from co-morbidity of mental illness especially depression with the associated suicide risk among this group of people. Government should also intensify the use of psycho education in the overall preventive measure for HIV/AIDS.

\section{Limitations of the Study}

A number of limitations were noticed in the study. These include the non usage of equal number of both males and females in the 'cases' and the control group, the variation in age of the 'cases' and the control group and the use of only some sections of the depression and suicidality modules of the MINI, instead of the whole sections. These limitations were noted and will be addressed in future research.

\section{References}

1. Sharp PM, Hahn BH (2011) Origins of HIV and the AIDS pandemic. Cold Spring Harb Perspect Med 1: a006841.

2. Gottlieb MS (2006) Pneumocystis pneumonia--Los Angeles. 1981. Am J Public Health 96: 980-981.

3. Adeyi B, Philips J, Oluwole O and John A (2006) Aids in Nigeria: A Nation on the Threshold. Chapter 2 Harvard Center for Population and Development Studies.

4. Federal Republic of Nigeria: Global AIDs Response Progress Report 2012.

5. UNAIDS Report on the Global AIDs Epidemic 2010.

6. Presidential Emergency Plans for AIDs Relief (PEPFAR); Country Profile: Nigeria, 2008.

7. World Health Organization Executive Board 124th Session; Provisional Agenda Item 4.3 HIV/AIDs and Mental Health 2008. Geneva: WHO.

8. United Nations General Assembly Special Session (2010) UNGASS Progress Report: Nigeria.

9. Anderson J (2005) HIV and Mental Health: The Challenges of Dual Diagnosis. Mental Health Issue Brief. National Alliance of State and Territorial AIDs Directors.

10. Hutton HE, Lyketsos CG, Zenilman JM, Thompson RE, Erbelding EJ (2004) Depression and HIV risk behaviors among patients in a sexually transmitted disease clinic. Am J Psychiatry 161: 912-914.

11. Booth RE, Kwiatkowski CF, Weissman G (1999) Health-related service utilization and HIV risk behaviors among HIV infected injection drug users and crack smokers. Drug Alcohol Depend 55: 69-78.

12. Turner J and Kelly B (2000) Emotional Dimensions of Chronic Disease. West African Journal of Medicine 17: 124-128.

13. Igwe MN, Uwakwe R, Ahanotu CA, Onyeama GM, Ndukuba AC et al. (2013) Factors Associated with Depression and Suicide among Patients with Diabetes Mellitus and Essential Hypertension in a Nigerian Teaching Hospital. African Health Sciences 13: 68-77.

14. Rodin G, Voshart K (1986) Depression in the medically ill: an overview. Am J Psychiatry 143: 696-705.

15. American Psychiatric Association (2000) Diagnostic and Statistical Manual of Mental Disorder, Fourth Edition, Test Revision (DSM-IVTR). American Psychiatric Association; Washington DC.

16. Rabkin JG, Charles E, Kass F (1983) Hypertension and DSM-III depression in psychiatric outpatients. Am J Psychiatry 140: 1072-1074.

17. Ickovics JR, Hamburger NE, Vlahov D, Schoenbaum EE, Schuma P, et al. (2001) Mortality, CD4 Cells Count decline and Depressive Symptoms among HIV - Seropositive Women: Longitudinal Analysis from the HIV Epidemiology Research Study. Journal of the American Medical Association 285: 1466-1474.

18. Stall R, Mills TC, Williamson J, Hart T, Greenwood G, et al. (2003) Association of co-occurring psychosocial health problems and increased vulnerability to HIV/AIDS among urban men who have sex with men. Am J Public Health 93: 939-942.

19. Rosenberger PH, Bornstein RA, Nasrallah HA, Para MF, Whitaker CC, et al. (1993) Psychopathology in human immunodeficiency virus infection: lifetime and current assessment. Compr Psychiatry 34: 150-158.

20. Morrison MF, Petitto JM, Ten Have T, Gettes DR, Chiappini MS, et al. (2002) Depressive and anxiety disorders in women with HIV infection. Am J Psychiatry 159: 789-796.

21. Noguiera CL (2006) Anxiety and Depression. Assessment before Antiritroviral Treatment in Brazil. Journal of AIDS Care 18: 529-336.

22. Komiti A, Judd F, Grech P, Mijch A, Hoy J, et al. (2001) Suicidal behaviour in people with HIV/AIDS: a review. Aust N Z J Psychiatry 35: 747-757.

23. Gibbie T, Mijch A, Ellen S, Hoy J, Hutchison C, et al. (2006) Depression and neurocognitive performance in individuals with HIV/AIDS: 2-year follow-up. HIV Med 7: 112-121.

24. Bing EG, Burnam MA, Longshore D, Fleishman JA, Sherbourne CD, et al. (2001) Psychiatric disorders and drug use among human 
Citation: Onyebueke GC, Okwaraji Fe (2015) Depression and Suicide Risk among HIV Positive Individuals Attending an Out Patient HIVI Aids Clinic of a Nigerian Tertiary Health Institution . J Psychiatry 18: 182. doi:10.4172/2378-5756.1000182

Page 8 of 8

immunodeficiency virus-infected adults in the United States. Arch Gen Psychiatry 58: 721-728.

25. Sebit MB (1995) Neuropsychiatric HIV-1 infection study: in Kenya and Zaire cross-sectional phase I and II. Cent Afr J Med 41: 315-322.

26. Ovuga E, Boardman J, Wasserman D (2005) The prevalence of depression in two districts of Uganda. Soc Psychiatry Psychiatr Epidemiol 40: 439-445.

27. Olley BO, Seedat S, Nei DG, Stein DJ (2004) Predictors of major depression in recently diagnosed patients with HIV/AIDS in South Africa. AIDS Patient Care STDS 18: 481-487.

28. Petrushkin H, Boardman JE (2005) Psychiatric disorders in HIV Positive individuals in urban Uganda. Psychiatric Bulletin 29: 455-458.

29. Sale S, Gudanya M (2008) Prevalence and factors associated with depression in HIV/AIDS Patients aged 15-25 years at the Aminu Kano Teaching Hospital. Nigerian Journal of child and Adolescent mental health 20: 95-99.

30. Ndu AC, Arinze O, Aguwa E, Obi I (2011) Prevalence of depression and role of support groups in its management. A study of adult HIV/AIDS Patents attending HIV/AIDS clinic in a tertiary health facility in South East Nigeria. Journal of Public health and Epidemiology 3: 182-186.

31. Olisa VO, Baiyewu O, Sheikh T (2011) Depression undiagnosed and the effects of quality of life in outpatients with HIV at a Nigerian University Teaching Hospital. African Journal of Aids Research 10: 247-254.

32. Alfonso CA, Cohen MA, Aladjem AD, Morrison F, Powell DR, et al. (1994) HIV seropositivity as a major risk factor for suicide in the general hospital. Psychosomatics 35: 368-373.

33. Harris EC, Barrowclough BM (1995) Suicide as an outcome of medical disorders among patients attending a hospital based general outpatient clinic. African Journal of medical science 7: 207-210.

34. Wells KB, Golding JM, Burnam MA (1988) Psychiatric disorder in a sample of the general population with and without chronic medical conditions. Am J Psychiatry 145: 976-981.

35. Marzuk PM, Tierney H, Tardiff K, Gross EM, Morgan EB, et al. (1988) Increased risk of suicide in persons with AIDS. JAMA 259: 1333-1337.
36. Kizer KW, Green M, Perkins CI, Doebbert G, Hughes MJ (1988) AIDS and suicide in California. JAMA 260: 1881

37. Israelski DM, Prentiss DE, Lubega S, Balmas G, Garcia P, et al. (2007) Psychiatric co-morbidity in vulnerable populations receiving primary care for HIV/AIDS. AIDS Care 19: 220-225.

38. Starace F (1995) Epidemiology of suicide among persons with AIDS. AIDS care 7: 5123-5128.

39. Hughes D, Kleespies P (2001) Suicide in the medically ill. Suicide Life Threat Behav 31 Suppl: 48-59.

40. Perry S, Jacobsberg LB, Fishman B, Frances A, Bobo J, et al. (1990) Psychiatric diagnosis before serological testing for the human immunodeficiency virus. Am J Psychiatry 147: 89-93.

41. Taylor, DW (1994) The calculation of sample size and power in planning experiments. Department of epidemiology and biostatistics. McMaster university. Hamilton Ontario Canada 1-23.

42. Sheehan DV, Lecrubier Y, Sheehan KH, Amorim P, Janavs J, et al. (1998) The Mini-International Neuropsychiatric Interview (M.I.N.I.): the development and validation of a structured diagnosticpsychiatric interview for DSM-IV and ICD-10. J Clin Psychiatry 59 Suppl 20: 22-33.

43. Okwaraji FE. Assessment of psychosocial problems in parenting sickle cell children in Enugu - Nigeria. Journal of college of Medicine. 6: 22-24

44. Kelly B, Raphael B, Judd F, Perdices M, Kernutt G, et al. (1998) Suicidal ideation, suicide attempts, and HIV infection. Psychosomatics 39: 405-415.

45. Eferakaya E (1981) A Drug and Suicide attempt in Benin City. British Journal of psychiatry138: 35-39.

46. Regier DA, Boyd JH, Burke JD Jr, Rae DS, Myers JK, et al. (1988) Onemonth prevalence of mental disorders in the United States. Based on five Epidemiologic Catchment Area sites. Arch Gen Psychiatry 45: 977-986.

47. Weissman MM, Klerman GL (1977) Sex differences and the epidemiology of depression. Arch Gen Psychiatry 34: 98-111.

48. Robins LN, Helzer JE, Weissman MM, Orvaschel H, Gruenberg E, et al. (1984) Lifetime prevalence of specific psychiatric disorders in three sites. Arch Gen Psychiatry 41: 949-958. 